\title{
Facial subcutaneous emphysema of late onset after frontal sinus fracture
}

\author{
Enfisema subcutâneo facial de início tardio após fratura do seio frontal
}

\author{
Andreia Filipa Miranda Mota $^{1}$, Virgínia Machado ${ }^{1}$, Sofia Peças $^{1}$, Alexandra Emílio ${ }^{1}$, Eduarda Marisa Vicente $^{1}$
}

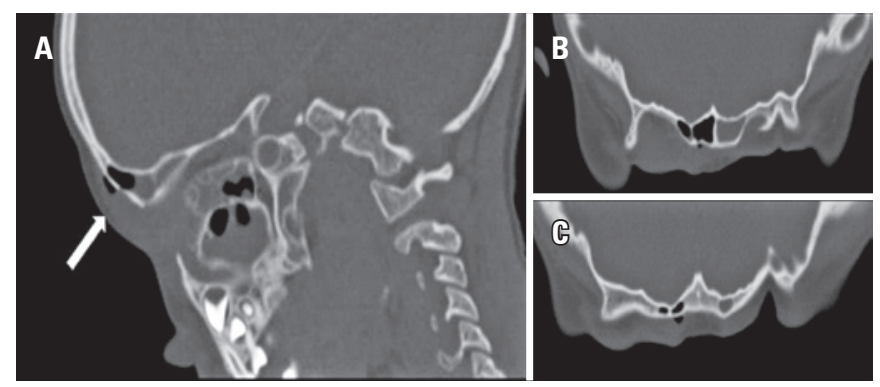

Figure 1. (A) Right parasagittal plane, (B) supraorbital transverse plane and (C) frontal transverse plane

A 5-year-old boy with previous history of frontal sinus fracture, 2 years ago, with conservative treatment and no current surgical follow-up. Upon admission, he had sudden onset of fever, severe swelling over the right eyelid and supraciliary region, and painful ocular movement. Physical examination showed no other alterations, therefore, excluding neurological compromise. Laboratory tests revealed raised inflammatory markers. For staging the extent of inflammation and exclude intracranial complications a computed tomography scan of the head and orbits was performed and revealed right frontal and periorbital swelling extending to postseptal area without optic nerve involvement. In addition, we observed subcutaneous emphysema around a break in the continuity of the anterior wall of frontal sinus table and a process of acute pansinusitis with air-fluid levels involving maxillary, ethmoid, sphenoid and frontal sinuses; there was no abscess formation. We admitted the diagnosis of orbital cellulitis and facial subcutaneous emphysema due to pansinusitis. Facial subcutaneous emphysema has been reported as an acute complication of head trauma. ${ }^{(1-4)}$
However, in this case, it was caused by a late complication of past bone fracture, probably triggered by an acute process of frontal sinusitis, which is a rare complication.

Subcutaneous emphysema is just one of the complications associated with pediatric head trauma, which also includes seizures, epidural, subdural or intracranial haemorrhage, cerebral veins and sinus thrombosis, cranial nerve injury, cerebrospinal fluid fistulas and pneumocephalus. ${ }^{(1,2,5-7)}$ The majority of these complications occur mainly in acute phase. Although, pneumocephalus and seizures can also be a late complication. Physicians should be aware of both acute and long-term complications of head trauma in order to ensure prompt and adequate intervention, and therefore, guarantee better outcomes. ${ }^{(1-8)}$

\section{REFERENCES}

1. Brasileiro BF, Cortez AL, Asprino L, Passeri LA, de Moraes M, Mazzonetto $R$, et al. Traumatic subcutaneous emphysema of the face associated with paranasal sinus fractures: a prospective study. J Oral Maxillofac Surg. 2005; 63(8):1080-7.

2. Ellis E 3rd, el-Attar A, Moos KF. An analysis of 2,067 cases of zygomatico-orbital fracture. J Oral Maxillofac Surg. 1985;43(6):417-28.

3. Roccia F, Griffa A, Nasi A, Baragiotta N. Severe subcutaneous emphysema and pneumomediastinum associated with minor maxillofacial trauma. J Craniofac Surg. 2003:14(6):880-3.

4. Zakaria R, Khwaja H. Subcutaneous emphysema in a case of infective sinusitis: a case report. J Med Case Rep. 2010;4:235.

5. Choi YY, Hyun DK, Park HC, Park CO. Pneumocephalus in the absence of craniofacial skull base fracture. J Trauma. 2009;66(2):E24-7.

6. Traumatic brain injury and coma. In: Kliegman RM, Marcdante KJ, Jenson HB, Behrman RE. Nelson essentials of pediatrics. 5th ed. Philadelphia: Elsevier Saunders; 2006. p.853-65.

7. Zachariades N, Mezitis M. Emphysema and similar situations in and around the maxillo-facial region. Rev Stomatol Chir Maxillofac. 1988;89(6):375-9.

8. Von Arx DP, Gilhooly M. An unusual presentation of orbital floor fracture. $\mathrm{Br} J$ Oral Surg. 1983;21(2):117-9.

\footnotetext{
'Centro Hospitalar de Setúbal, EPE, Setúbal, Portugal.

Corresponding author: Andreia Filipa Miranda Mota - Rua do Serrado, 6, 3d direito - Massamá - Zip code: 2735-628 - Agualva-Cacém, Portugal - Phone: + 351 96385-5759 - E-mail: andreiafilipam.mota@gmail.com Received on: Sep 7, 2015 - Accepted on: Oct 28, 2015
}

DOI: 10.1590/\$1679-45082016Al3532 